\title{
HUBUNGAN ANTARA PERILAKU SISWA SAAT BELAJAR DI KELAS DENGAN HASIL BELAJAR BIOLOGI PADA POKOK BAHASAN KEANEKARAGAMAN HAYATI SISWA KELAS X SMA NEGERI 14 BATAM
}

\section{THE RELATIONSHIP BETWEEN STUDENTS' BEHAVIOUR DURING STUDYING TIME AND BIOLOGY LEARNING OUTCOMES ON BIODIVERSITY SUBJECT AT CLASS X SMA NEGERI 14 BATAM}

\author{
Ressy Bella Putri ${ }^{1}$, Notowinarto ${ }^{2 *}$, Fenny Agustina $^{3}$ \\ ${ }^{123}$ Program Studi Pendidikan Biologi, FKIP, Universitas Riau Kepulauan,Batam. \\ *Korespondensi: notowinarto@gmail.com
}

\begin{abstract}
ABSTRAK
Penelitian ini bertujuan untuk mengetahui hubungan antara perilaku siswa saat belajar di kelas dengan hasil belajar Biologi pada pokok bahasan keanekaragaman hayati siswa kelas X SMA Negeri 14 Batam. Penelitian ini terdiri dari dua variabel, yaitu perilaku siswa (variabel bebas) dan hasil belajar siswa (variabel terikat). Jenis penelitian ini adalah Ex post facto menggunakan metode kuantitatif dengan pendekatan korelasional. Populasi dalam penelitian ini adalah siswa kelas X MIA SMA Negeri 14 Batam yang berjumlah 112 siswa dengan jumlah sampel sebanyak 84 siswa. Teknik sampling yang digunakan adalah simple random sampling. Pengumpulan data menggunakan angket tertutup sebanyak 23 pernyataan dan dokumentasi hasil belajar. Hasil uji prasyarat menujukkan bahwa data normal dan homogen. Melalui korelasi Product moment Pearson didapat nilai koefisien korelasi $(r)$ sebesar 0,598 tergolong cukup. Hasil Uji signifikansi dengan uji t didapat nilai ${ }_{h} \geq(6,761>1,989)$ maka signifikan, dengan kontribusi variabel X terhadap Y sebesar 35,8\%. Hal ini menunjukkan adanya hubungan yang erat antara perilaku siswa saat belajar dikelas dengan hasil belajar Biologi pada pokok bahasan keanekaragaman hayati siswa kelas X SMA Negeri 14 Batam, dengan demikian $\mathrm{H}_{\mathrm{o}}$ ditolak.
\end{abstract}

Kata Kunci : Perilaku siswa, Hasil Belajar, Biologi.

\begin{abstract}
This study aims to determine the relationship between students' behaviordurimh studying time and Biology learning outcomes on biodiversity subject at class X SMA Negeri 14 Batam. This study consisted of two variables, namely the students' behavior (independent variable) and student learning outcomes (dependent variable). This research was an ex post facto use of quantitative methods with the correlational approach. The population in this study was class X students of MIA SMA Negeri 14 Batam, amounting 112 students with total sample was 84 students. The sampling technique was simple random sampling. To ccollect data, questionnaires with 23 statements and learning outcomes records were used. The test results showed that the data is normal and homogeneous. By using Pearson product moment correlation, it obtained correlation coefficient $(r)$ of 0.598 quite enough. The results of significance test with t test values obtained $h \geq(6.761>1.989)$ it is significant, with the contribution of variable
\end{abstract}


$X$ to Y 35.8\%. It shows that there is a relation between students' behavior during studying time and Biology learning outcomes on biodiversity subject at class X SMA Negeri 14 Batam, so that Ho was rejected.

Keywords: Mind mapping, Outcomes learning, Analysis $T_{\text {test }}$ PENDAHULUAN

Dalam undang-undang Nomor 20 Tahun 2003 tentang sistem pendidikan nasional menyatakan bahwa "Pendidikan nasional bertujuan untuk berkembangnya potensi siswa agar menjadi manusia yang beriman bertakwa kepada Tuhan Yang Maha Esa, berakhlak mulia, sehat, berilmu, cakap, kreatif, mandiri dan menjadi warga negara yang demokratis serta bertanggung jawab". Untuk mewujudkannya diperlukan partisipasi yang baik dari siswa agar tercipta suasana belajar yang kondusif guna mencapai tujuan pembelajaran yang telah ditetapkan dalam rencana pelaksanaan pembelajaran (RPP).

Saat belajar di kelas masih banyak ditemui siswa yang berperilaku kurang baik, seperti menganggu teman yang sedang melakukan pengamatan, berbuat curang dengan meniru karya temannya, membuat keributan saat presentasi, sering datang terlambat, serta masih banyak perilaku lainnya yang dapat menyebabkan proses pembelajaran terganggu. Hal tersebut jauh dari kompetensi inti pembelajaran Biologi kelas X yang menyatakan bahwa siswa diharapkan mampu mengamalkan perilaku jujur, disiplin, tanggung jawab, peduli, (gotong royong, kerjasama, toleransi, damai), santun, responsif, dan proaktif.

Perilaku merupakan tindakan, tingkah laku atau aktivitas dari manusia itu sendiri yang mempunyai cakupan yang sangat luas, yang umumnya dapat terlihat, antara lain: berjalan, berbicara, tertawa, belajar, menulis, membaca, dan sebagainya. Perilaku juga diartikan sebagai suatu reaksi psikis seseorang terhadap lingkungannya. Perilaku siswa akan sangat mempengaruhi suasana belajar di kelas, untuk itu perilaku siswa sangat diharapkan mengarah pada perilaku positif yang mendukung pembelajaran, menciptakan iklim belajar yang kondusif dan dapat merangsang siswa untuk bersaing secara sehat dan meraih prestasi. Namun faktanya siswa yang berada dalam suatu kelas memiliki berbagai karakter yang berbeda-beda, tidak semua siswa dapat berperilaku baik, siswa yang berperilaku cenderung negatif dapat mengganggu proses pembelajaran, seorang siswa yang berperilaku buruk akan merugikan dirinya sendiri dan orang-orang yang ada disekitarnya. 
Dari uraian latar belakang diatas, maka identifikasi masalah sebagai berikut: a) Partisipasi siswa untuk mewujudkan suasana belajar yang kondusif saat pembelajaran Biologi masih kurang; b) Perilaku siswa yang masih jauh dari kompetensi inti pembelajaran Biologi; c) Banyak siswa yang menganggap pembelajaran Biologi sulit dan membosankan; dan d) Hasil belajar Biologi yang masih rendah.

\section{METODOLOGI}

Jenis penelitian ini adalah penelitian ex post facto, yaitu penelitian yang digunakan untuk menyelidiki kemungkinan hubungan sebab-akibat dengan cara berdasarkan atas pengamatan terhadap akibat yang ada, mencari kembali faktor yang mungkin menjadi penyebab melalui data tertentu (Suryabrata, 2013). Metode yang digunakan dalam penelitian ini adalah kuantitatif dengan pendekatan korelasional.

Penelitian ini terdiri dari dua variabel, yaitu Perilaku siswa saat belajar di kelas sebagai variabel bebas (X) dan Hasil belajar Biologi sebagai variabel terikat (Y). Populasi dalam penelitian ini adalah siswa/siswi kelas X MIA SMA Negeri 14 Batam tahun ajaran 2014/2015 sebanyak 4 kelas yaitu berjumlah 112 siswa. Dalam penelitian ini teknik sampling yang digunakan adalah simple random sampling yang merupakan cara pengambilan sampel dengan menggunakan acak tanpa memperhatikan tingkatan dalam anggota populasi tersebut (Riduwan, 2011). Dalam menentukan ukuran sampel digunakan tabel Isaac dan Michael untuk tingkat kesalahan 5\%. Jumlah sampel yang digunakan sebanyak 84 siswa.

Penelitian terdiri dari 3 (tiga) tahap, yaitu: 1) tahap persiapan sebelum penelitian; 2) tahap pelaksanaan penelitian; dan 3) tahap penyelesaian penelitian. Teknik pengumpulan data yang digunakan adalah kuesioner berupa angket perilaku siswa saat belajar di kelas dengan skala likert dan dokumentasi hasil belajar keanekaragaman hayati.

\section{PEMBAHASAN}

Penelitian ini terlebih dahulu melakukan uji coba instrumen untuk mendapatkan data validitas dan reliabilitas. Validitas butir pernyataan angket dilaksanakan di kelas X MIA 3 SMA Negeri 14 Batam yang terdiri dari 28 siswa. Validitas instrumen dihitung menggunakan rumus 
Product Moment, dimana $n=28$ dan taraf signifikansi 5\% (0,05), maka nilai $\mathrm{r}_{\text {tabel }}$ adalah 0,374. Dari 41 butir pernyataan 23 soal dinyatakan valid dan 18 soal drop. Perhitungan reliabilitas terhadap 23 butir pernyataan tersebut didapat nilai $\mathbf{r}_{11} 0.870>0.60$, sehingga angket dinyatakan reliabel. Setelah dilakukan uji instrument, maka angket disebarkan kepada sampel yang berjumlah 84 siswa, dengan deskripsi data sebagai berikut:

Tabel 1. Rekapitulasi Deskripsi Data Penelitian

\begin{tabular}{|c|c|c|c|}
\hline \multirow[b]{2}{*}{ NO } & \multirow[b]{2}{*}{ STATISTIK DESKRIPTIF } & \multicolumn{2}{|c|}{ DATA PENELITIAN } \\
\hline & & $\begin{array}{c}\text { PERILAKU SISWA } \\
(\mathrm{X})\end{array}$ & HASIL BELAJAR (Y) \\
\hline 1 & Jumlah Sampel (n) & 84 & 84 \\
\hline 2 & Jumlah Total Data $(\square)$ & 6337 & 5753 \\
\hline 3 & Data Maksimum (Max) & 100 & 85 \\
\hline 4 & Data Minimun (Min) & 49 & 45 \\
\hline 5 & Rentang (r) & 51 & 40 \\
\hline 6 & Rerata (Mean) & 75.44 & 68.49 \\
\hline 7 & Modus (Mo) & 86 & 76 \\
\hline 8 & Median (Me) & 76.5 & 69.5 \\
\hline 9 & Standar Deviasi (S) & 10.45 & 9.68 \\
\hline 10 & Varians $\left(\mathrm{S}^{2}\right)$ & 109.29 & 93.70 \\
\hline
\end{tabular}

Hasil uji normalitas data perilaku siswa saat belajar di kelas diperoleh nilai Asymp.Sig. sebesar 0.383. Nilai Asymp.Sig. (0.383) > $\alpha 0.05$ sehingga data berdistribusi normal. Sedangkan pada nilai hasil belajar diperoleh Asymp.Sig. sebesar 0.591. Nilai Asymp.Sig.

$(0.591)>\alpha 0.05$ yang berarti data berdistribusi normal. Perhitungan homogenitas data diperoleh nilai Sig. Sebesar 0.141. Nilai Sig. $0.141>\alpha$ 0.05, maka dapat disimpulkan bahwa data homogen. Hasil pengujian menunjukkan bahwa prasyarat normalitas data untuk pengujian hipotesis terpenuhi, maka dengan demikian analisis dapat dilanjutkan untuk menguji hipotesis penelitian yang diajukan.

Pengujian hipotesis menggunakan korelasi Product Moment Pearson untuk melihat kekuatan hubungan antara variabel bebas yaitu variabel perilaku siswa $(\mathrm{X})$ dengan variabel terikat hasil belajar (Y). Didapat nilai koefisien korelasi $(r)$ sebesar 0,598. Nilai koefisien korelasi sebesar 0,598 tergolong cukup atau sedang (berada pada interval 0,400-0,599) serta 
memiliki nilai positif dan searah, hal ini berarti semakin baik perilaku siswa saat belajar di kelas maka akan semakin tinggi pula nilai hasil belajarnya, begitu pula sebaliknya, semakin buruk perilaku siswa saat belajar di kelas maka akan semakin rendah nilai hasil belajarnya. Untuk mengetahui data dan nilai koefisien korelasi yang diperoleh dapat mencerminkan keadaan populasi atau tidak, maka dilakukan perhitungan signifikansi koefisien korelasi dengan menggunakan uji t. Dari Uji signifikansi diperoleh nilai $h$ sebesar 6,671, apabila $h \geq$ maka signifikan dan sebaliknya apabila $h \leq$ maka tidak signifikan. Besarnya dengan dk sebesar 82 (n - 2) pada taraf kepercayaan $5 \%$ adalah sebesar 1,989 . Karena $h \geq(6,761>1,989)$ maka signifikan, artinya data dapat digeneralisasikan pada populasi dimana sampel diambil. Koefisien determinasi (KD) menunjukkan nilai sebesar 0,358 atau sebesar $35,8 \%$ dari hasil $\left(\mathrm{R}^{2}\right.$ x 100\%). Artinya variasi perubahan nilai hasil belajar Biologi pada pokok bahasan keanekaragaman hayati dipengaruhi oleh perilaku siswa sebesar 35,8\% dan sisanya dipengaruhi oleh variabel lain yang tidak diteliti.

Hasil uji statistik pada hopotesis, hasil adalah terdapat hubungan yang signifikan antara perilaku siswa saat belajar di kelas dengan hasil belajar Biologi pada pokok bahasan keanekaragaman hayati siswa kelas X SMA Negeri 14 Batam. Hasil penelitian ini telah membuktikan bahwa perilaku siswa saat belajar di kelas mempengaruhi hasil belajar yang diperoleh, namun rendahnya hasil belajar pada pokok bahasan keanekaragaman hayati siswa kelas X MIA SMA Negeri 14 Batam tidak sepenuhnya disebabkan oleh perilaku siswa, hal ini dibuktikan oleh perhitungan persentase pada masing-masing indikator dan diperoleh persentase total sebesar 64,27 \% yang tergolong pada kriteria kuat atau baik artinya perilaku siswa saat belajar di kelas termasuk pada kategori baik.

Adapun persentase perilaku siswa saat belajar di kelas berdasarkan masing-masing indikator yaitu:

Tabel 2. Persentase Sebaran Angket

\begin{tabular}{clcc}
\hline NO & INDIKATOR & PERSENTASE $\mathbf{( \% )}$ & KRITERIA \\
\hline 1 & Jujur & 47,02 & Cukup \\
2 & Disiplin & 79,76 & Kuat \\
3 & Tanggung Jawab & 55,16 & Cukup \\
4 & Peduli & 77,48 & Kuat
\end{tabular}




\begin{tabular}{llcc}
5 & Santun & 68,21 & Kuat \\
6 & Responsif & 70,95 & Kuat \\
7 & Proaktif & 51,29 & Cukup \\
\hline & TOTAL & $\mathbf{6 4 , 2 7}$ & Kuat \\
\hline
\end{tabular}

Penelitian diatas juga didukung oleh penelitian yang telah dilakukan oleh Halimah (2013) dalam „Pengaruh Perilaku Siswa terhadap Hasil Belajar pada Mata Pelajaran Pkn di Kelas XI MAS AL-hidayah Kampung Rakyat Tahun Pelajaran 2012/2013“e. Didapati hubungan signifikan yang tergolong sedang antara variabel X dengan variabel Y dengan nilai korelasi sebesar 0,515. Hal serupa juga dibuktikan pada penelitian yang dilakukan oleh Sugiwan (2014) dalam "Pengaruh Perilaku Belajar terhadap Hasil Belajar Siswa pada Mata Pelajaran Ekonomi Kelas XI di Madrasah Aliyah Negeri Lipatkain Kecamatan Kampar Kiri Kabupaten

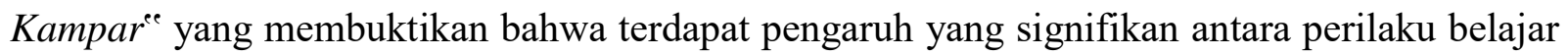
dengan hasil belajar siswa dengan tingkat korelasi yang kuat yaitu nilai sebesar 0,799 $(\mathrm{r}=$ $79,9 \%)$

Menurut Soeharto (2004) dalam Suharyat (2009) perilaku adalah hasil proses belajar mengajar yang terjadi akibat dari interaksi dirinya dengan lingkungan sekitarnya yang diakibatkan oleh pengalaman-pengalaman pribadi. Perilaku siswa saat belajar di kelas muncul sebagai reaksi terhadap proses pembelajaran yang sedang berlangsung di kelas tersebut, yang dipengaruhi oleh banyak faktor. Pada pencapaian hasil belajar, perilaku termasuk pada faktor internal yang mempengaruhi proses belajar mengajar siswa, hal tersebut diungkapkan oleh Aunurrahman (2011) dalam Karwati dan Priansa (2014) bahwa beberapa faktor internal yang mempengaruhi hasil belajar belajar siswa diantaranya ciri khas/karakteristik siswa, sikap atau perilaku terhadap belajar, motivasi belajar, konsentrasi belajar, mengolah bahan belajar, menggali hasil belajar, rasa percaya diri dan kebiasaan belajar.

Terdapat hubungan yang signifikan antara perilaku siswa saat belajar di kelas dengan hasil belajar Biologi pada pokok bahasan keanekaragaman hayati siswa kelas X SMA Negeri 14, artinya semakin baik perilaku siswa saat belajar di kelas maka cenderung semakin baik pula hasil belajarnya, sebaliknya jika perilaku di kelas tidak baik maka cenderung tidak baik pula hasil belajarnya. 


\section{KESIMPULAN}

Berdasarkan hasil analisis data dalam penelitian ini, maka dapat disimpulkan bahwa terdapat hubungan yang signifikan antara perilaku siswa saat belajar di kelas dengan hasil belajar Biologi pada pokok bahasan keanekaragaman hayati siswa kelas X SMA Negeri 14 Batam tahun ajaran 2014/2015. Hal ini dibuktikan $h \geq$ pada taraf signifikansi 5\% $(6,761>1,989$. Tingkat hubungan antara variabel X (perilaku siswa) dengan variabel Y (hasil belajar) berada pada interval sedang atau cukup $(0,40$ - 0,599) dengan nilai korelasi $(r)$ sebesar 0,598. Hubungan perilaku siswa saat belajar di kelas dengan hasil belajar Biologi pada pokok bahasan keanekaragaman hayati adalah sebesar 35,8 \% sedangkan selebihnya dipengaruhi oleh faktor lain.

\section{REFERENSI}

Anshori, M. dan D. Martono, 2009. Biologi 1: untuk Sekolah Menengah Atas (SMA) - Madrasah Aliyah (MA) Kelas X. Pusat Perbukuan Departemen Pendidikan Nasional, Jakarta.

Farida, A., 2014. Pilar-pilar Pembangunan Karakter Remaja; Metode Pembelajaran Aplikatif untuk Guru Sekolah Menengah. Nuansa Cendekia, Bandung.

Halimah, N., 2013. Pengaruh Perilaku Siswa terhadap Hasil Belajar pada Mata Pelajaran Pkn di Kelas XI MAS AL-hidayah Kampung Rakyat Tahun Pelajaran 2012/2013. (Skripsi). Universitas Negeri Medan, Medan.

Firdaus, R. (2016). Analisis Kesesuaian Lokasi Untuk Aplikasi Teknologi Terumbu Buatan Untuk Peningkatan Hasil Perikanan Dan Rehabilitasi Lingkungan Laut. DIMENSI, 4(1).

Hook, P. dan A. Vass, 2011. Strategi Manajemen Perilaku. Penerjemah: P.A. Lestari, Erlangga, Jakarta.

Karwati, E. dan D.J. Priansa, 2014. Manajemen Kelas (Classroom Management) Guru Professional yang Inspiratif, Kreatif, Menyenangkan, dan Berprestasi. Alfabeta, Bandung.

Kurniasih, I. dan B, Sani, 2014. Implementasi Kurikulum 2013: Konsep \& Penerapan. Kata Pena, Surabaya. 
Muhtadi, A., 2011. Pengembangan Sikap dan Perilaku Siswa yang Bermoral dalam Kegiatan Pembelajaran di Sekolah. Majalah Ilmiah Pembelajaran. 7: 96-107.

Sugiyono, 2013. Metode Penelitian Kuantitatif, Kualitatif, dan R\&D. Alfabeta, Bandung.

Sulistyowati, E., W.H. Omegawati dan M.L. Hidayat., 2013. Buku Guru: Biologi untuk SMA/MA Peminatan Matematika dan Ilmu-ilmu Alam. Intan Pariwara, Klaten.

Suparman, 2011. Studi Perbedaan Kualitas Sikap Jujur Siswa Kelas III SMTA Negeri Kota Madiun. Jurnal Interaksi. 7: 1-13. 
Ressy Bella Putri, Notowinarto, Fenny Agustina : Hubungan antara perilaku siswa...

Umroni, A., 2010. Majalah Ilmiah Warta Cendana: Mengenang Hari Keanekaragaman Hayati International. (Edisi ke-3), Balai Penelitian Kehutanan, Kupang.

Widodo, B., 2013. Perilaku Disiplin Siswa Ditinjau dari Aspek Pengendalian Diri (Self Disclosure) pada Siswa SMK Wonosari Caruban Kabupaten Madiun. Widya Warta. 1: 140-151.

Yamin, M., 2013. Strategi \& Metode dalam Model Pembelajaran. Referensi (Gaung Persada Press Group), Jakarta. 